\title{
Trends of Higher Education Evolution in the Multiethnic Environment of Mining Regions
}

\author{
Oksana Greenwald ${ }^{1, *}$ \\ ${ }^{1}$ Kemerovo State University, Institute of Philology, Foreign Languages and Mediacommunications, \\ Department of Foreign Languages, 650000, 6 Krasnaya st., Kemerovo, Russia
}

\begin{abstract}
Internationalization of higher education as a national strategy has resulted in intensive growth of the number of international students in the regional universities. A current multiethnic educational environment requires defining the trends of the regional higher education evolution aimed at training both students and educators for productive and efficient cross-cultural interaction hence enhancing the quality of higher education. The analysis of the researches devoted to sustainable development of Kuzbass (West Siberia, Russia), national and international normative legal documents regulating the implementation of multicultural education, and the experience in training international students at the flagship university of Kuzbass - Kemerovo State University - has been conducted. As a result, the following trends of the multiethnic higher education evolution have been defined: the purposeful organization of multiethnic educational environment; the shaping of tolerance to multiethnic environment in both students and teaching staff; the training of university teaching staff for professional activity in multiethnic environment, particularly, for designing the content of multicultural education along with applying modern interactive educational technologies. The defined trends promote higher quality of education and regional human capital as indispensable provision for sustainable development of the coal mining region Kuzbass.
\end{abstract}

\section{Introduction}

In 2015 the UN General Assembly defined the key sustainability issues facing the world today that are stated in the Declaration "Transforming our world: the 2030 Agenda for Sustainable Development". The Declaration has become a supranational strategy for the world's development. The goals of sustainable development can be grouped into three main trends: the development of economy, the development of ecology and social development [1].

We have analyzed the articles on sustainable development of a coal mining region Kuzbass (West Siberia, Russia) published in 2017-2020 and can conclude that sustainable development of Kuzbass is considered primarily as the development of coal mining industry, economy and ecology of the region (see https://www.e3s-conferences.org 20172020).

\footnotetext{
* Corresponding author: greenwald.ru@,rambler.ru
} 
Notwithstanding the fact that economic and ecological development of the region is of great urgency, sustainable development of Kuzbass is impossible without the increase of human capital. Therefore, regional universities and institutes of higher education play an undeniable role in economic and social progress of Kuzbass as they provide highly qualified personnel for the industries and businesses of the region capable to implement innovative development trends in economy and ecology thus enhancing living standards of the population and region's competitiveness at the national and international levels $[2,3]$. Economic and social progress of Kuzbass, in its turn, promotes enhancing human capital by preventing the population, especially the youth, from leaving the region that is currently considered as one of the most serious problems of Kuzbass [4].

Furthermore, one of the regional higher education strategies along with the national ones is the internationalization of higher education that makes provision for the involvement of international students to take higher education programs in regional universities as well as retaining international students as a potentially highly educated labour force. According to the Department of Education and Science of Kemerovo RegionKuzbass in 2019-2020 academic year Kemerovo State University - the flagship university of the region - trained students from 25 countries.

As a result of internationalization, the increasing number of international students in the regional universities and higher education institutions has resulted in the appearance of multiethnic and multicultural educational environment that has made it urgent to develop and implement the strategy aimed at training both students and teaching staff for efficient intercultural interaction, thus promoting the quality of higher education.

The analysis of the world's strategies aimed at the organization of educational process in multiethnic and multicultural environment allows defining two main strategies: monocultural education (assimilation) and multicultural education (or the dialogue of cultures). Both strategies strive for the creation of a harmonious multiethnic society, though being different in the ways of achieving the goal.

The strategy of monocultural education (assimilation) as the means of uniting the nation of a multiethnic and multicultural state dominated in the world's educational policy until 1970s. The essence of the strategy implies that the culture of the dominant nation with its values and traditions prevails in education; therefore, cultural minorities are inevitably assimilated. The examples are the USSR experience in creating a super nation - "the Soviet Nation" - on the basis of the Russian language and culture; or the USA ideology of "a melting pot" that infers the consolidation of multiethnic population of the country on the basis of the language and culture of white Anglo-Saxon Protestants.

The strategy of assimilation has resulted in two opposite subsequent effects. On the one hand, social, economic, and educational preferences to the dominant cultures have led to the assimilation of ethnic and cultural minorities to different degrees in the dominant cultural environment. On the other hand, the segregation of ethnic and cultural minorities has provoked the appearance of secluded all-sufficient ethnic enclaves that actively resist their assimilation, thus, becoming the centers of political and criminal tension in a lot of cities of Europe and the USA.

The movement for democratic rights and freedoms of ethnic and cultural minorities, increase of international cooperation along with migration of population determined the search for alternative educational strategies in a multinational state. As the result, the strategy of multiculturalism or "the dialogue of cultures" appeared. The main principles of multiculturalism are defined in UN documents: the Universal Declaration of Human Rights (1948); the International Covenant on Economic, Social and Cultural Rights; the Convention on the Elimination of All Forms of Racial Discrimination; the Declaration on the Rights of Persons Belonging to National or Ethnic, Religious and Linguistic Minorities; 
the UNESCO Convention and Recommnendation against Discrimination in Education and others.

Multiculturalism proclaims cooperation or "the dialogue of cultures" in a multinational state. Education as a public institution is to train the youth for cooperation with representatives of different cultures by means of educating about other cultures, bringing up respect to a language and cultural values of national and ethnic minorities, shaping intercultural competence and ethnic tolerance in both students and educators as the subjects of education [5].

Multicultural education is proclaimed a national strategy in the Russian Federation. Its essence, goals, tasks and main principles are declared in the Constitution of RF, in the State Law on Education, in the Concept of Multicultural Education in Higher School and other documents. Nevertheless, only several articles concerning the implementation of multicultural education strategy in the system of the regional higher education have been found among the articles devoted to sustainable development of Kuzbass. The urgency for the development of perspective trends of multiethnic higher education for sustainable development of the coal mining region Kuzbass has inspired our research.

\section{Materials and methods}

To achieve the goal of the development multiethnic higher education trends the analysis of the articles devoted to sustainable development of Kuzbass, national and international normative legal documents regulating the implementation of multicultural education, and the experience in training international students at the flagship university of Kuzbass Kemerovo State University - has been conducted.

\section{Results and discussion}

On the basis of the conducted analysis the following trends of multiethnic higher education evolution have been defined: the purposeful organization of multiethnic educational environment at a university; the shaping of tolerance to multiethnic environment in both students and teaching staff; the training of university teaching staff for professional activity in multiethnic environment. Herein under are the defined trends in greater detail.

1. The purposeful organization of multiethnic educational environment at a university.

The purposeful organization of educational subjects' interaction in the university multiethnic environment is the first and foremost condition of implementation multicultural education strategy at a university. It is fulfilled by the efforts of different university departments and services made with the purpose to promote social and cultural adaptation and instruction of international students on the host country traditions; legal, psychological and any other counselling of international students; creating favorable psychological climate for productive and efficient native and international students' collaboration by involving them in the joint practical, cultural, volunteer activity; training and development students' and educators' skills of cross-cultural communication in the multiethnic university environment [6].

2. The shaping of tolerance to multiethnic environment in both students and teaching staff.

Multiethnic and multicultural university environment makes it urgent to shape both students' and educators' tolerance to multiethnic and multicultural university environment. The Declaration of the Principles of Tolerance proclaimed by UNESCO at the United Nations General Assembly in 1995 defines tolerance as recognition and respect of the values of other cultures' and ethnos' [7]. 
The concept of tolerance is closely connected with the ideas of multicultural education as it represents a universal human principle providing admission and recognition of the behavior, language and cultural peculiarities of another ethnos in the process of crosscultural communication. Therefore, the shaping of tolerance presupposes upbringing of respect, acknowledgement of other cultures, training the ability for cross-cultural dialogue and collaboration. Students' tolerance is shaped by means of the content and methods of education. Effective educational technologies that promote the shaping of students' tolerance are person-oriented and cooperative technologies [8].

Furthermore, multiethnic and multicultural university environment makes it necessary to shape educators' tolerance to ethnically and culturally diverse studentship as well. More than that, it may be stated that ethnic tolerance of the teacher is the major factor of bringing up ethnic tolerance in students, the foundation of "the dialogue of cultures" and efficient educational activity of international students in a host university [6].

The most important demands to the educator are the following: one's own persistent cultural identity that is expressed by perception oneself as a bearer of particular cultural traditions; demonstration of the positive attitude towards other cultures thus becoming a mediator of panhuman cultural values; professional mastery; psychological orientation to tolerance, cooperation, interaction and collaboration of cultures. Moreover, educator's ethnic tolerance implies reflection one's own values, prejudices and stereotypes toward other cultures and cross-cultural interaction; understanding the equal value of any cultural, religious, social and ethnic groups that international students represent.

3. The training of university teaching staff for professional activity in multiethnic environment.

The methodical preparedness of university teaching staff for professional activity in multiethnic environment is the basis for implementation multicultural education concept and efficient training of international students in Russian universities. It is expressed by the ability of an educator to organize a positive dialogue of cultures, that is, to design the content of multicultural education as well as to apply modern interactive educational technologies.

The conception of the dialogue of cultures in higher education can be realized by means of including the information about cultural features of different ethnic communities represented in the location (a state, a republic, a region or a university) in the curriculum and social subject content. Moreover, the cultural component of the social subject content should point out at panhuman values uniting people of different ethnic background as well as interdependence of national cultures in the whole world culture of the humanity.

A university curriculum subject Foreign Languages, being a compulsory one for all students of any training program in all Russian universities, provides an opportunity for university teaching staff to realize and implement the conception of the dialogue of cultures by highlighting linguacultural and social features of both a taught language nation and representatives of different ethnic communities learning a foreign language jointly in a particular class of a university.

Let us describe our experience of designing the multicultural content of a university curriculum subject Foreign Languages for multiethnic student groups learning English at Kemerovo State University. To demonstrate social and cultural peculiarities of their nationality both Russian and international students were given a task to make up presentations in English about their native country, its education system, traditions, celebrations, outstanding people, etc. By comparing social, cultural and language peculiarities such presentations contribute to bringing up understanding and acceptance of ethnic and cultural differences of English language learners and, consequently, tolerance to the representatives of other ethnos. For example, presentations devoted to the New Year celebration in Russia, Great Britain and Central Asia countries (where the vast majority of 
international students in Kemerovo State University come from) showed that, in spite of different traditions to celebrate this holiday by different nationalities and religions, it is a joyful event uniting all the people.

The methodical preparedness of university teaching staff for applying modern interactive technologies of multicultural education in their professional activity requires developing and implementing efficient educational patterns of interaction for cooperative teaching students of different ethnic groups with the purpose to train highly qualified specialists by the university. The communicative nature of a university subject Foreign Languages allows applying educational technologies that promote intercultural competence development by acquiring means of verbal and non-verbal cross-cultural communication. Herein under are the results of our research aimed at development and implementation efficient educational technologies for teaching English in multiethnic groups of university students.

The goal of a university subject Foreign Languages is to shape students' competence to communicate, either orally or in writing, in a foreign language for the purpose of conducting efficient cross-cultural and interpersonal interaction in their future professional activity. An appropriate competence can be shaped while communicating a taught foreign language; hence, it must be the only language to be spoken at Foreign Languages lessons.

However, there is a considerable number of international students who are beginners or at the elementary level of English. They need focusing their attention on formal features of a taught foreign language, its grammar and spelling rules, derivative models, etc. Consequently, a teacher may need to code-switch, that is, "to switch from the linguistic system of one language or dialect to that of another" [9]. In this case code-switching is a conscious and pragmatic method purposefully used by a teacher, as English is a foreign language for both teachers and students [10].

The analysis of publications devoted to code-switching in foreign language teaching shows that its occurrence at a lesson can be classified into three main groups $[11 ; 12 ; 13$; 14]:

1. Curriculum access aimed at: lowering down cognitive load while learning grammar structures of a foreign language; understanding terminology of a subject in content and language integrated learning (CLIL); highlighting the most relevant information; promoting foreign language vocabulary acquisition.

2. Classroom management aimed at: regulating students' behavior; organizing classroom activity by giving instructions in a native language; achieving greater involvement in classroom activity.

3. Regulation of interpersonal relations with the purpose to express an emotion or praise; to low down students' anxiety; to create comfortable and friendly atmosphere at the lesson; to build up casual interaction with students; to make up communicative situation for practicing language skills.

However, we had to analyze if it is possible and reasonable to code-switch at foreign language lessons in multiethnic groups of students, whose native languages are unallied with either Russian as the language of teaching or with each other (for instance, native languages of international students - Farsi and Turkic languages). The abovementioned educational and affective goals of code-switching (in our case from English into Russian) may prove to be ineffective for international students as they may cause additional hardship and cognitive load.

Our research has shown that to use code-switching for classroom management and organizing classroom activity of international students by giving instructions in Russian is unproductive and unreasonable. It has proved to be more useful to teach students some necessary wording of tasks and exercises in English at the initial stage of studies. Moreover, it is reasonable to give up code-switching at the advanced level of teaching 
English when the goal of the subject shifts from learning specifics of a foreign language to its practical application in quasi-professional situations. At the advanced level students have already acquired necessary foreign language vocabulary and developed language skills allowing them to communicate in a foreign language quite efficiently. Therefore, it is advisable to avoid code-switching in the advanced level groups of international students.

Nevertheless, in the groups of international students who are at a lower level of English, it is very difficult to avoid code-switching; thus, international students have to study English by means of Russian as a teaching language. It should be mentioned that according to Interaction Hypothesis a foreign language learner unconsciously acquires L2 (a taught foreign language) adopting it to already existing L1 (a native language) competence [13]. That is why learning a foreign language becomes more efficient when a teacher draws learners' attention to similarities and differences between L1 and L2. As for international students this implies comparing L1 (their native language, mostly Farsi or Turkic languages) to L3 (English) via L2 (Russian as a lingua franca). The technique has proved to be productive for acquiring not only English as a taught foreign language, but for enhancing Russian language competence that contributes much to the improvement of international students' academic performance in general.

Furthermore, a teacher is not only "a transmitter" of knowledge but a moderator of the dialogue of cultures in the multiethnic educational environment of a university. Consequently, a teacher must be able to organize efficient cross-cultural interaction in the multiethnic group of students thus eliminating ethnic stereotypes and promoting the development of ethnic tolerance and intercultural competence [15]. The most suitable educational technologies, aimed at development students' ethnic tolerance and intercultural competence, are those implying cooperation and collaboration in carrying out a task such as a joint project work, role play, and work in ethnically diverse pairs or groups. The latter has proved to be the most useful at the lessons of English in multiethnic groups of students while training vocabulary, grammar and communicative skills. Dialogue-like technologies help to draw students' attention to different social and cultural patterns of communication highly important for valid and productive interaction in their future professional activity and practice them while imitating casual or professional situations.

\section{Conclusion}

To sum up, globalization and internationalization of higher education have resulted in multiethnic environment in the regional institutions of higher education that determines to define the trends of higher education evolution corresponding to the current global strategy of education in a multicultural society, namely, multicultural education. The defined trends of higher education evolution are the following: the purposeful organization of multiethnic educational environment at a university; the shaping of tolerance to multiethnic environment in both students and teaching staff; the training of university teaching staff for professional activity in multiethnic environment.

The organization of multiethnic educational environment at a university is performed by cooperative efforts of all university departments and personnel and is aimed at social and cultural adaptation of international students along with creating favorable conditions for intercultural communication and education. The shaping of tolerance to multiethnic environment in both students and teaching staff is realized by means of integrating specific cultural content concerning international students' cultural background into the subjects and courses taught at the university along with the application of interactive educational technologies. The training of university teaching staff for professional activity in multiethnic environment means preparing the personnel of a university for designing the content of multicultural education as well as for applying modern interactive educational 
technologies. The conducted research allows us to say that in teaching English the appropriate technologies are code-switching; comparing language features (a native language of international students (L1), Russian as lingua franca (L2), English as a taught foreign language (L3)); cooperative work in ethnically diverse pairs or groups.

The aforementioned trends of higher education evolution in multiethnic environment promote higher quality of education of both native and international graduates of regional universities and higher education institutions, thus enhancing the quality of human capital as indispensable provision for sustainable development of the coal mining region Kuzbass.

\section{Acknowledgment}

The reported study was funded by RFBR according to the research project № 19-013$00805 \mathrm{~A}$ "The models of pedagogical interaction in foreign language learning process in multiethnic higher education environment".

\section{References}

1. Transforming our world: the 2030 Agenda for Sustainable Development. URL: https://sdgs.un.org/2030agenda

2. A. Krechetov, E3S Web Conf. 15, 00001 (2017)

3. V. Mikhalchenko, I. Seredkina, E3S Web Conf. 105, 04031 (2019)

4. E. Morozova, E. Pastukhova, T. Logunov, E3S Web Conf. 174, 04044 (2020)

5. J.A. Banks, C.A.M. Banks, Multicultural Education: Issues and Perspectives (Wiley, London, 2013)

6. O. Greenwald, A. Resenchuck, T. Sergeychick, E3S Web Conf. 105, 04019 (2019)

7. The Declaration of the Principles of Tolerance by UNESCO-1995. URL: http://unesco.org

8. S. Kolomiets, E. Medvedeva, and A. Perevalova, E3S Web Conf. 174, 04026 (2020)

9. Merriam-Webster Unabridged Dictionary. URL: https://www.merriamwebster.com/dictionary/code-switching

10. T. Mokgwathi, V. Webb, Studies in the Languages of Africa, 44, 3, 108-125 (2013)

11. J. Bruen, N. Kelly, Language Learning Journal, 45(3), 368-381 (2017)

12. H. Cahyani, M. de Courcy, J. Barnett, International Journal of Bilingual Education and Bilingualism, 21(4), 465-479 (2018)

13. D. Domalewska, International Journal of Languages, Literature and Linguistics, 1, 6-9, (2015)

14. S. Gwee, V. Saravanan, International Journal of Multilingualism, 15(2), 117-134 (2016)

15. D. Beyazkurk, J. E. Kesner, International Education Journal 6, 547-554 (2005) 